\title{
Age-Dependent Effects C57BL/6 Genetic Mutations under Mice Models of Parkinson's Disease on Motor Ability
}

\section{Zhixiang Chen ${ }^{1}$, Shengmin Zhao', Yaoyue Wei' ${ }^{1}$, Lin Hou' ${ }^{1}$}

\begin{abstract}
${ }^{1}$ Department of Biochemistry and Molecular Biology, Medical College of Qingdao University, Qingdao 266021, China
\end{abstract}

\begin{abstract}
As literature reported, C57BL/6 A53T mutant human alpha-synuclein under the mice is one successful model related to Parkinson's disease(PD). In previous studies, over-accumulation of alpha-synuclein which lead to lewy body, were revealed to cause impairment on motor ability in Parkinson's disease mouse model. Nevertheless, in the open filed test and the rota-rod test, hyperactivity and motor ability improvements at 12 months old was found in our study.
\end{abstract}

Keywords: Parkinson’s Disease; Motor Ability; Hyperactivity; Genetic Mutation

\begin{abstract}
Introduction
Parkinson's Disease(PD) is the one of the most common neurodegenerative disorders, affecting five million people worldwide. The loss of dopamine neurons in the substantia nigra and the formation of intraneuronal inclusions called Lewy bodies account for the typical pathological characterize of PD. Alpha-Synuclein is the major structural component of Lewy bodies, and it has been accepted by most researchers that the overexpression of alpha-Syn protein in neurons is problematic.To model the disease,one approach was to create transgenic mice that accumulated and aggregated the A53T mutant of a-Syn, which causes an autosomal dominant form of PD in humans [1] .The A53T a-Syn mouse model successfully imitated many important features of synucleinopathy, including age-dependent neurodegeneration and reduced locomotion within a certain perid and age-dependent loss of motor performance $[2,3,4]$.
\end{abstract}

The pharmacological management of PD is complex,and drug therapy were adopted by most patient, however,most drugs have potential harmful side effects.Study the PD models may provide useful evidences for new therapy.In the research, we found some new points connected with aging of mouse model.At the same time,some behavior confused us because The trans-genetic mice behave deferent from PD patients to some extent.

\begin{abstract}
Materials and Methods
Animals

In our study, we used three-month-old, nine-monthold and twelve-month-old C57BL/6 mice to simulate the correlation between the process of motor symptoms with age. We kept mice at room temperature under one day/one night cycle and housed 4 animals/cage. Every one week, we cleaned their home-cages and provided with food and water. Mice were initially obtained from Jackson Laboratories (Bar Harbor, ME). Mice with the mutant gene were generated on A53T genetic background with C57B1/6 wild phenotype $[9,10]$. Previous studies have proved that the homozygous mice were embryonic death or die, therefore we used the heterozygous mice in our tasks. All experimental animals were kept with approval of the Institutional Animal Care and Use Committee. Mice used in accordance with the Committee on the Ethics of Animal Experiments of Qingdao University.
\end{abstract}

\section{Open field Test \\ Open field test was used to evaluate locomotor activity, exploratory behavior and tensity of mice in an extraneous environment. Mice are born with the fear to a new environment, therefore mice prefer to spend more time in the central area rather than the surrounding area. However, the exploration characteristics would prompt mice to produce the motivation to explore the novel environment. Therefore, the frequency, duration and total distance}

This article is published under the terms of the Creative Commons Attribution License 4.0

Author(s) retain the copyright of this article. Publication rights with Alkhaer Publications.

Published at: http://www.ijsciences.com/pub/issue/2015-10/

DOI: 10.18483/ijSci.855; Online ISSN: 2305-3925; Print ISSN: 2410-4477 
of the mice in a new environment were used to reflect the autonomous activity and exploratory behavior. In this task, mice were placed in the center area and allowed $10 \mathrm{~min}$ of free exploration, which is made by transparent plexi, equipped with the ANY-maze video tracking system to record activity.

\section{Rota-rod Test}

Rota-rod apparatus was used for estimating the balance and motor coordination of mice. At the training session, the animals were placed on the rotarod for $2 \mathrm{~min}$ without rotation. Then the rod was accelerated to a speed of 4-40 rpm for $5 \mathrm{~min}$ in total, three trails one day for 3 days continuously. The parameters of the test were recorded by the system.

\section{Statistical analysis}

All data were expressed as mean values \pm S.E.M. Ttest was adopted to analyze the parameters at the probe session between the control and trans-genetic groups (SPSS 19.0 software, $n \geq 6$ for each group). *P $<0.05$ was considered to be statistically significant.

\section{Results}

Hyperactivity in C57BL/6 genetic mutations was age-dependent

Locomotor activity was evaluated in C57BL/6 genetic mutations and wild-type mice at $3,9,12$ months old. To determine the time process and locomotor activity of development of C57BL/6 genetic mutations, we used the open field test to assess this parameters. Previous study revealed that genetic mutations traveled significantly greater distances compared with wild-type mice at 2 months and 12 months of age[5, 6, 7]. In our task, we did not confirm this notion at 3-month-old mice[Fig. 1A]. During the $10 \mathrm{~min}$ of free exploratory activity, the 3 and 9 month-old mice traveled the virtually identical distance in genetic mutations and wild-type[Fig. 1A]. Nevertheless, at 12 months, the distance increased significantly compared with matched group[Fig. 1A]. At all ages, no difference was observed between genetic mutations and control group in the time spent in the center area, as well as the frequency and the speed(data not show).

Genetic mutation mice reveals abnormal improvements on motor ability

Related to disease progression, 3, 9 and 12 months of age mice were used to do rota-rod test. Our findings indicated mice showed similar behaviors in motor coordination at 3 and 9 months old[Fig. 1B]. However, at 12 months of age, the duration that mice stayed on the rod exhibited a sharp increase[Fig. 1B]. Results from open field and rota-rod tests demonstrated that genetic mutation mice develop age-related hyperactivity and gross motor behavior, as a previous study described[8]. Additionally, we did not found these mice develop locomotor activity and alteration motor ability on the onset of period[Fig 1B].
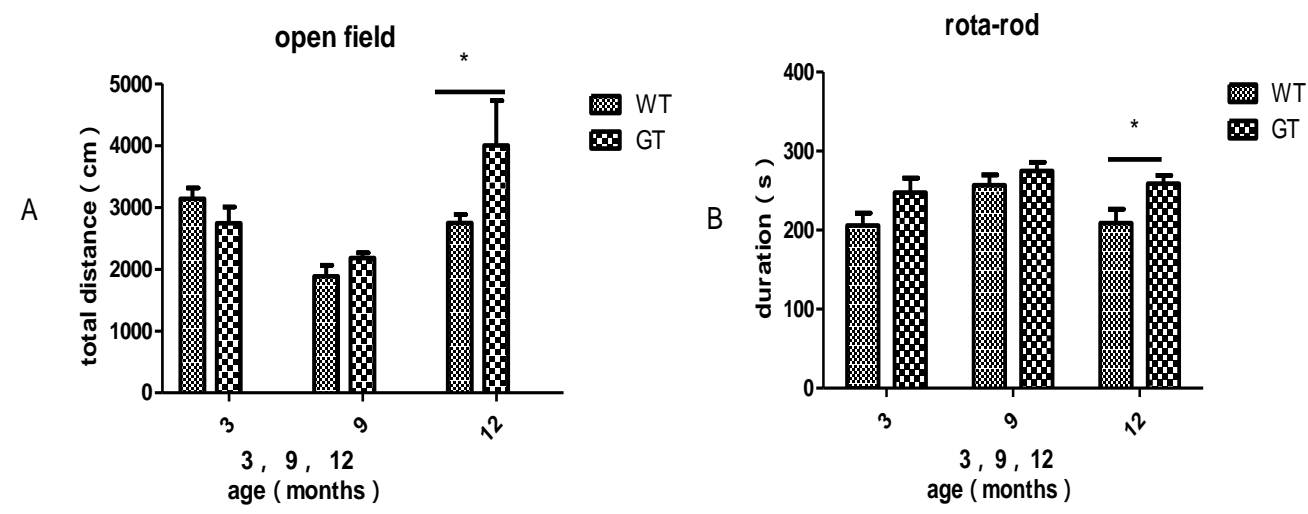

Figure 1. Age-dependent effects C57BL/6 genetic mutations mice on locomotor activity and motor ability. A, total distance in all area of open field test at 3,9, 12 months of age. B, latency to fall on the rod was recorded by the rota-rod apparatus(IITC Life Sciences, Wood Hills, CA). All data were expressed as mean values \pm S.E.M. T-test. $* \mathrm{P}<0.05, * * \mathrm{P}<0.01, \mathrm{n} \geq 6$.

\section{Discussion}

Combined, these behaviors at 3,9, 12 months of age and these time point lied well in advance of the early and late-onset of locomotor activity and motor abnormalities. These data indicated the genetic mutation mice exhibited inverse to PD patients. Numerous clinical reports manifested that antihyperactivity and motor disorders to PD patients[9, $10,11]$. At opposite poles, in our tasks, we found the
3 and 9 month-old mice traveled the virtually identical distance in genetic mutations and wildtype[Fig. 1A]. Nevertheless, at 12 months, the distance increased significantly compared with matched group[Fig. 1A]. These results suggested that genetic mutation mice exhibited anti-anxiety behaviors at 12 month-old. In the rota-rod test, our findings indicated mice showed similar behaviors in motor coordination at 3 and 9 months old[Fig. 1B]. 
However, at 12 months of age, the duration that mice stayed on the rod exhibited a sharp increase[Fig. 1B]. These data were consistent with previous reports displayed that genetic mutation mice were hyperactive before the onset of motor dysfunction[12], compared with other reports that had testified the similar behavioral phenotypes[6, 13]. We do not know what the mechanisms are that lead to motor improvement at 12 months old in genetic mutation mice. There is a necessary to work hard to explore the unknown mechanisms. We expect that these findings may provide useful endpoints for estimating novel therapeutic interventions for PD.

\section{References}

1. Savitt JM, Dawson VL, Dawson TM (2006) Diagnosis and treatment of Parkinson disease: molecules to medicine. J Clin Invest 116: 1744-1754.

2. Ferrer I, Lopez-Gonzalez I, Carmona M, Dalfo E, Pujol A, et al. (2012). Neurochemistry and the non-motor aspects of PD. Neurobiol Dis 46: 508-526.

3. Lim SY, Lang AE (2010) The nonmotor symptoms of Parkinson's disease-an overview. Mov Disord 25 Suppl 1: S123-130.

4. Levy G, Tang MX, Louis ED, Cote LJ, Alfaro B, et al. (2002) The association of incident dementia with mortality in PD. Neurology 59: 1708-1713.

5. Dianca R. Graham and Anita Sidhu. Mice Expressing the A53T Mutant Form of Human Alpha-Synuclein Exhibit Hyperactivity and Reduced Anxiety-Like Behavior. J Neurosci Res . 2010 June ; 88(8): 1777-1783. doi:10.1002/jnr.22331.

6. Unger EL, Eve DJ, Perez XA, Reichenbach YX, Lee MK, Andrews AM. Locomotor hyperactivity and alterations in dopamine neurotransmission are associated with overexpression of A53T mutant human alpha-synuclein in mice. Neurobiol Dis 2006;21:431-443. [PubMed: 16230020]

7. Giros B, Jaber M, Jones S, Wightman R, Caron M. Hyperlocomotion and indifference to cocaine and amphetamine in mice lacking the dopamine transporter. Nature 1996;379:606-612. [PubMed:8628395]

8. Paumier KL, Sukoff Rizzo SJ, Berger Z, Chen Y, Gonzales C, et al. (2013) Behavioral Characterization of A53T Mice Reveals Early and Late Stage Deficts Related to Parkinson's Disease. PLoS ONE 8(8): e70274. doi:10.1371/journal.pone.0070274

9. Menza M, Robertson-Hoffman D, Bonapace A. Parkinson's disease and anxiety: cormorbidity and depression. Biol Psychiatry 1993;34:465-470. [PubMed: 8268331]

10. Shiba M, Bower J, Maraganore D, McDonald S, Peterson B, Ahlskog J, Schiad D, Rocca W. Anxiety and depressive disorders preceeding Parkinson's disease: a case control study. Mov Disord 2000;15:669-677. [PubMed: 10928577]

11. Marinus J, Leentjens A, Visser M, Stiggelbout A, van Hilten J. Evaluation of the hospital anxiety and depression scale in patients with Parkinson's disease. Clin Neuropharmocol 2002;25:318-324.

12. Unger EL, Eve DJ, Perez XA, Reichenbach YX, Lee MK, Andrews AM. Locomotor hyperactivity and alterations in dopamine neurotransmission are associated with overexpression of A53T mutant human alpha-synuclein in mice. Neurobiol Dis 2006;21:431-443. [PubMed: 16230020]

13. George S. $\alpha$-Synuclein transgenic mice exhibit reduced anxiety-like behavior. Exp Neurol 2008;210:788-792. [PubMed: 18295208] 